\title{
Perceptions of Fellowship Trainees in Public and Private Tertiary Care Hospitals of Karachi
}

\author{
Sadaf zia ${ }^{1}$, Maisam Abbas Onali ${ }^{2}$, Hina Yousuf ${ }^{3}$, Aria Masoom ${ }^{4}$, Asna Shahab ${ }^{5}$, Nabiha Amjad ${ }^{6}$ \\ ${ }^{1}$ Assistant Professor, Department of ENT, Head and Neck Surgery, Dow International Medical College, Karachi \\ ${ }^{2}$ Assistant Professor, Department of ENT, Head and Neck Surgery, Jinnah Medical and Dental College, Karachi \\ ${ }^{3}$ Assistant Professor, Department of Pediatric Surgery, Liaquat National Hospital and Medical College, Karachi \\ ${ }^{4}$ Assistant professor, Department of ENT, Bolan University of Medical and Health Sciences, Quetta \\ ${ }^{5}$ House Officer, Dow University Hospital, Karachi \\ ${ }^{6}$ House Officer, National Institute of Child Health, Karachi
}

\begin{abstract}
A B S TR ACT
Background: The issues pertaining to postgraduate medical education have been debated for long but there has been little contribution to this literature from developing countries. Therefore, a need to make an accurate assessment regarding current status of postgraduate training in Pakistan was felt and feedback from residents is the cornerstone of such an assessment. The objective of our study was to document perceptions of FCPS trainees of medical and surgical disciplines in private and public tertiary care hospitals of Karachi, Pakistan.

Material and Methods: This was a cross sectional survey of the medical and surgical FCPS trainees in three hospitals ( 1 public and 2 private) of Karachi Pakistan, conducted over a period of two months ( $1^{\text {st }}$ November 2018 to $31^{\text {st }}$ December 2018). A total of 325 participants selected by convenient sampling technique were included in the study. Data was collected through structured self-developed questionnaire and analyzed by SPSS version 16.0.

Results: The percentage of postgraduate trainees in private hospitals working for more than 80hours/week is higher than those working in public sector hospitals (59.4\% versus $42.4 \%)$. Topic presentation and Academic meetings (Conferences, Workshops and CMEs) were the most preferred teaching strategies in Postgraduate training (77.4\% and 77.5\%). About $62.7 \%$ of the residents believed that their program was in line with CPSP guidelines. Public sector hospitals were better in terms of medical benefits giving partial cover $(62.8 \%)$ than private sector $(P$-value $<0.001)$. Majority of trainees at private sector hospitals seemed satisfied with their working environment than at public hospital $(77.5 \%$ versus $12.5 \%)(P$-value $<0.001)$. Trainees perceived that the security arrangements at both public and private hospitals were not adequate, but in case of emergency private hospitals seemed to have better security response as compared to public hospitals ( $89 \%$ versus $23 \%$ ) with a significant difference of $<0.001$.

Conclusion(s): Perception of most of the postgraduate trainees is that they are being adequately trained for the challenges of an independent physician or surgeon.
\end{abstract}

Key words: Postgraduate training programs, Medical education, Trainees perception

Authors' Contribution: Correspondence:

${ }^{1-3}$ Conception; Literature research; Sadaf Zia

manuscript design and drafting; 3-6Critical Email:sadaf.zia@duhs.edu.pk

analysis and manuscript review; Data analysis; Manuscript Editing.

Cite this article. Zia S, Onail MA, Yousaf H, Masoom A, Shahab A, Amjad N. Perceptions of Fellowship Trainees in Public and Private Tertiary Care Hospitals of Karachi. J Islamabad Med Dental Coll.2020; 9(1): 28-34. Doi: 10.35787/jimdc.v9i1.392
Article info:

Received: August 3, 2019

Accepted: March 7, 2020

\section{Funding Source: Nil}

Conflict of Interest: Nil 


\section{Introduction}

Effective teaching and training requires not only a well-motivated and a dedicated trainee but also demands a vigorous teaching faculty who help guarantee a vibrant environment for residents education and research. ${ }^{1-3}$ College of Physicians and Surgeons of Pakistan (CPSP) is the leading institute awarding Fellowships to trainees in various disciplines through structured guidelines and continuous surveillance. ${ }^{4}$

During postgraduate training of a doctor, it is expected that their existing clinical knowledge and skills will be improved, they will be exposed to a broad range of procedures and will benefit from mentoring by leaders in their respective fields. ${ }^{1}$ To assess such parameters, the Accreditation Council for Graduate Medical Education (ACGME) of USA identified six learning outcomes for postgraduate medical education. ${ }^{5-7}$ These include patient care, medical knowledge, interpersonal communication skills, professionalism, practice-based learning, and system-based practice. In this perspective, every postgraduate institute has to provide a detailed list of training objectives in a particular field and explain how they will be delivered, monitored and measured. Moreover, regular feedbacks from the trainees regarding their satisfaction with training and supervision, working hours and work environment must be made part of the program. ${ }^{8}$

We believe that there are many areas of concerns in the current fellowship training across the country and these need to be dealt individually. Trainees seem dissatisfied with their training structures and long tiring working hours. ${ }^{9}$ Lack of financial support, inadequate infrastructure and security concerns are also major problems. These are further aggravated if the faculty is also unable to provide a conducive learning environment. Unfortunately, in Pakistan majority of the institutes where postgraduate training programs are being conducted lack uniformity in structure and therefore fail to monitor and measure the progress and performance of the trainees according to the laid protocol. ${ }^{10}$ The issues pertaining to postgraduate medical education have been debated for long in developed countries, however, there has been little contribution to this literature from developing countries. ${ }^{11,12}$ Therefore, there is a need to make an accurate assessment regarding current status of postgraduate training program in Pakistan with perceptions/feedbacks from the residents (FCPS trainees) in private and public hospitals of Karachi, as the cornerstone of such an assessment.

\section{Material and Methods}

This was a cross-sectional survey of the medical and surgical FCPS trainees in three hospitals of Karachi Pakistan, conducted over a period of two months ( $1^{\text {st }}$ November 2018 to $31^{\text {st }}$ December 2018). One public-sector hospital (Dow University of Health sciences) and two private-sector hospitals (Liaquat National Hospital and Jinnah Medical College Hospital) were included. Data was collected through self-developed structured questionnaire. Informed consent was obtained from all the participants. Confidentiality and anonymity of the participants was ensured. Ethical approval for the study was obtained from the Ethical Review and Research Committee of Jinnah Medical and Dental College, Karachi.

All trainees registered with CPSP as FCPS II train ee $\mathrm{S}$ in medicine and surgery were included in the study. A sample size of 268 was calculated by OpenEpi calculator with 5\% margin of error and 95\% confidence interval. Data was analyzed in SPSS version 16.0. Chi-square test was applied to test significance and $P$-value $<0.05$ was taken as significant.

Variables of interest included working hours, teaching strategies and satisfaction of trainees with 
their training program. Satisfaction with training program was measured in terms of alignment with CPSP guidelines, working environment, medical benefits, interaction with supervisor and guidance for research etc. Trainees were also surveyed for provision of security on daily basis as well in case of emergency.

\section{Results}

A total of 325 participants were included in the study, out of which 103 (31.7\%) trainees were doing residency in a private teaching hospital and 222 participants (68.3\%) belonged to a public sector training hospital. About 195 (60\%) residents were enrolled for FCPS in Medicine and Allied and 130 (40\%) were enrolled for FCPS in Surgery and Allied. Most of the employees were getting monthly stipend of Rs. 65,000 .

According to our data $66.8 \%$ of the residents believed that their program was in line with CPSP guidelines while $33.2 \%$ thought it was partially or not in line with CPSP guidelines.

Percentage of trainees in private hospitals working for more than 80 hours/week was higher than those working in public sector hospitals $(59.4 \%$ versus $42.4 \%$ ), however the difference was not statistically significant (Table I). Data regarding the frequency of postgraduate teaching methods showed that "Topic presentation" and "Academic meetings" (conferences, workshops and CMEs) were the most preferred teaching strategies in Postgraduate training $(77.4 \%$ and $77.5 \%$ respectively).

"Teaching rounds" and "Topic presentation" were equally preferred in public and private medical institute. Long case discussion was employed more in private hospital than public hospitals (44\% versus 30\%) (Table II). However, trainees in private hospital got significantly greater opportunities to attend "Morbidity Mortality meetings" and
"Conferences and workshops" than the residents in public sector hospitals ( $P$-value $<0.001)$ (Table II).

\begin{tabular}{|c|c|c|c|c|}
\hline & \multicolumn{3}{|c|}{ Average working hours / week } & \multirow[b]{2}{*}{ Total } \\
\hline & $\begin{array}{c}>80 \\
\text { hours/week }\end{array}$ & $\begin{array}{c}80 \\
\text { hours/week }\end{array}$ & $\begin{array}{c}<80 \\
\text { hours/week }\end{array}$ & \\
\hline \multirow{2}{*}{$\begin{array}{l}\text { Private } \\
\text { Hospitals }\end{array}$} & 18 & 28 & 56 & 102 \\
\hline & $17.6 \%$ & $27.5 \%$ & $54.9 \%$ & $100 \%$ \\
\hline \multirow{2}{*}{$\begin{array}{l}\text { Public } \\
\text { Hospital }\end{array}$} & 44 & 85 & 94 & 223 \\
\hline & $19.7 \%$ & $38.1 \%$ & $42.2 \%$ & $100 \%$ \\
\hline \multirow{2}{*}{ Total } & 62 & 113 & 150 & 325 \\
\hline & $19.1 \%$ & $34.8 \%$ & $46.2 \%$ & $100 \%$ \\
\hline
\end{tabular}

\begin{tabular}{|c|c|c|c|c|}
\hline & & $\begin{array}{c}\text { Public } \\
\text { Hospital }\end{array}$ & $\begin{array}{l}\text { Private } \\
\text { Hospital }\end{array}$ & $\begin{array}{c}P \text { - } \\
\text { value }\end{array}$ \\
\hline \multirow{2}{*}{$\begin{array}{l}\text { Teaching } \\
\text { Round }\end{array}$} & Yes & $125(38.4 \%)$ & $55(16.9 \%)$ & \multirow{2}{*}{0.624} \\
\hline & No & $97(29.8 \%)$ & $48(14.7 \%)$ & \\
\hline \multirow{2}{*}{$\begin{array}{l}\text { Topic } \\
\text { Presentation }\end{array}$} & Yes & $158(48.6 \%)$ & $80(24.6 \%)$ & \multirow{2}{*}{0.218} \\
\hline & No & $64(19.6 \%)$ & $23(7.07 \%)$ & \\
\hline \multirow{2}{*}{$\begin{array}{l}\text { Long Case } \\
\text { Discussion }\end{array}$} & Yes & $66(20.30 \%)$ & $46(14.1 \%)$ & \multirow{2}{*}{0.008} \\
\hline & No & $156(48 \%)$ & $57(17.5 \%)$ & \\
\hline \multirow{2}{*}{$\begin{array}{l}\text { Morbidity } \\
\text { and Mortality } \\
\text { meetings }\end{array}$} & Yes & $62(19.07 \%)$ & $77(23.69 \%)$ & \multirow[b]{2}{*}{$<0.001$} \\
\hline & No & $144(44.30 \%)$ & $41(12.61 \%)$ & \\
\hline \multirow{3}{*}{$\begin{array}{l}\text { Academic } \\
\text { Meeting* }\end{array}$} & Yes & $84(25.84 \%)$ & $79(24.30 \%)$ & \multirow{3}{*}{$<0.001$} \\
\hline & No & $40(12.30 \%)$ & $9(2.76 \%)$ & \\
\hline & ST\$ & $97(29.84 \%)$ & $15(4.61 \%)$ & \\
\hline
\end{tabular}

*Academic meetings included Conferences, CME, Workshop \$ST-Sometimes

Trainees at public sector hospitals recorded that they were being partially covered (62.8\%) in terms of medical benefits while most of the trainees in private sector hospital believed that their institute had no such policy $(81.4 \%)$ ( $P$-value $<0.001)$. A greater number of trainees at private sector hospital seemed satisfied with their working environment than at public hospitals $(77.5 \%$ versus 12.5\%) ( $P$-value $<0.001)$. They also documented that they received regular feedback from their supervisors (Private $53.9 \%$ versus Public 31.8\%), had exposure to proper assessment techniques (Private $62.7 \%$ versus Public 32.3\%) and were 


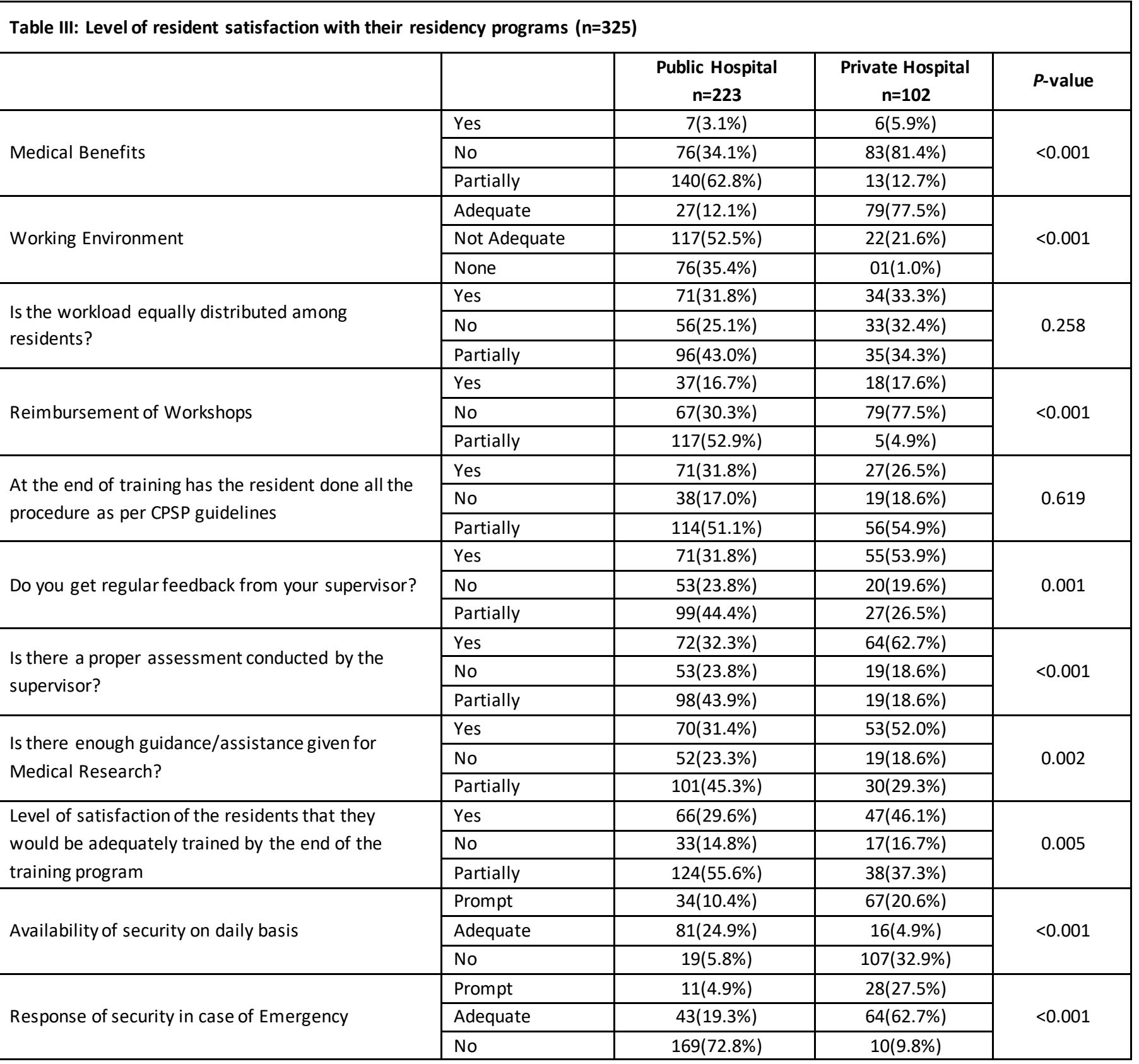

satisfied that they will be adequately trained by the end of training (Private $46.1 \%$ versus Public $29.6 \%$ ) (Table III).

Trainees perceive that the security arrangements at both public and private hospitals were not adequate but in case of emergency, private hospitals seem to have better response in term of security as compared to public hospitals (89\% versus $23 \%)(P<0.001)$ (Table III).

\section{Discussion}

This study showed that there is a need to make an accurate assessment of current status of postgraduate training program in Pakistan with perceptions of the residents (FCPS trainees) in private and public sector hospitals of Karachi, as the cornerstone of such an assessment. 
An interesting finding in our study was that more residents of Medical and allied specialty were working more than 80 hours/week as compared to Surgical specialties $(P<0.001)$. This is in contrast to a study done by Sameer-ul-Hassan which showed the surgical trainees to be working more than their colleagues in medicine. ${ }^{12}$ This discrepancy could be because most of our study participants belonged to Medicine and Allied specialty. The reduction in training hours has a direct impact on the quality and exposure of trainees to difficult clinical problems. This has been widely discussed in the literature and the satisfaction level of trainees with their training programs has been reported to drop internationally. ${ }^{13-15}$

Our study gives a satisfaction level that once they qualify, the residents would be capable enough to deal with all major medical and surgical problems independently ( $P$-value 0.005$)$. Public and private sector trainees are confident that they would have an adequate training by the end of their training period. However, the trainees of public sector hospitals showed less confidence for the level of training for surgical procedures as compared to Private hospital residents who had a slightly better confidence level for procedures. This is in contrast to widely held view that government institutes are better for postgraduate training owing to bulk of patients coming to these hospitals. ${ }^{10}$

According to the residents' perceptions, academic teaching has a good format and is structured in both public and private teaching hospitals with teaching ward round and topic presentations being the most widely used method of teaching. Long case presentation, morbidity and mortality meetings and conferences are less frequently used for training. Many teaching programs are trying new innovation methods of teaching and learning to improve quality of postgraduate medical training. ${ }^{16,17}$ In our study, residents at both public (125; 56.4\%) and private sector (55; 54.9\%) hospitals revealed that teaching ward rounds and topic presentations are used equally. This was followed by long case discussion and morbidity and mortality meetings.

Only $32.4 \%$ of the public sector trainees believed that proper assessment was being conducted, 43.69\% believed that it was being done only partially in contrast to private hospital trainees (62.1\% and $27.1 \%$ ). The student teacher interaction has an important impact on the teaching and learning process. In case of regular feedback, the private hospital trainees were again at advantage than public hospital trainees. The private sector residents were being more regularly given feedbacks on their performance $(P$-value $<0.001)$. The support and guidance which is required for medical research was given more promptly in private sector hospitals than government hospital ( $P$-value 0.002$)$. Tabassum et al emphasized the importance of giving timely feedback which most faculty members might not be able to give because of time constraints faced during patient care. ${ }^{8}$

Adequate facilities for on-call trainees are important for creating a good working environment. The work environment includes provision of room, access to reading materials and computers, clean water and cafeteria. These were either not present or were inadequate in public sector hospital. In contrast, private sector hospital are providing for the basic necessities of the postgraduate trainees $(P$-valve $<0.001) .{ }^{1}$ The importance of working environment was also emphasized by Weigl et al ${ }^{18}$ and the inadequacy of provisions for the trainees highlighted by Biggs and khaloon LE respectively. ${ }^{4,19}$

Provision of safety and security for an on-call trainee doctor is of utmost concern and should be present at all times in the Hospital. It is noted with concern that $84 \%$ of public hospital residents did not have comprehensive security arrangements. In private hospital despite the presence of security 
arrangements, the response of security was inadequate (meaning that when called for help by the doctor they either did not reach the venue at all or were very late). This was a major source of concern for the trainees $(P$-value $<0.001) .{ }^{19}$

A good salary package also plays an important role in the overall well-being and capacity for learning of a trainee. In our study this was an important factor. This observation has also been noted by Hameed et al in a study performed on 99 surgical post graduate trainees. They found that salary was also one of the factors leading to job dissatisfaction and lesser appreciation of wellbeing in trainees, ${ }^{20}$ an observation similar to our study.

Limitation: A larger sample comprising of FCPS trainees of Medicine and Surgery all over the Pakistan would give a more complete picture of the present situation of postgraduate training in the country.

\section{Conclusion}

Most of the postgraduate trainees perceive that they are being adequately trained for the challenges of an independent clinical practice.

\section{Acknowledgment}

We are grateful to Syed Fida Hussain for his help in data management.

\section{References}

1. Holmboe ES. Faculty and the Observation of Trainees' Clinical Skills: Problems and Opportunities. Acad Med. 2004; 79(1): 16-22. Doi: 10.1097/00001888-200401000-00006

2. Dyrbye L, Shanafelt T. A narrative review on burnout experienced by medical students and residents. Med Educ. 2016; 50(1): 132-49. Doi: 10.1111/medu.12927

3. Yousuf $A$, Ishaque S, Qidwai W. Depression and its associated risk factors in medical and surgical post graduate trainees at a teaching hospital: a cross sectional survey from a developing country. J Pak Med Assoc. 2011; 61(10): 968-73. PMID: 22356028
4. Biggs JSG. Postgraduate Medical Training in Pakistan: Observations and Recommendations. JCPSP. 2008; 18(1): 58-63

5. Chapman DM, Hayden $S$, Sanders $A B$, Binder LS, Chinnis $A$, Corrigan $K$, et al. Integrating the Accreditation Council for Graduate Medical Education Core competencies into the model of the clinical practice of emergency medicine. Ann Emerg Med. 2004; 43(6): 756-69. Doi: 10.1016/S0196064403013532

6. Dyne PL, Strauss RW, Rinnert S. Systems-based practice: the sixth core competency. Acad Emerg Med. 2002; 9(11): 1270-7. Doi: 10.1111/j.15532712.2002.tb01587.x

7. Swing SR. Assessing the ACGME general competencies: general considerations and assessment methods. Acad Emerg Med. 2002; 9(11): 1278-88. Doi: 10.1111/j.1553-2712.2002.tb01588.x

8. Zehra T, Tariq M, Ali SK, Motiwala A, Boulet J. Challenges of providing timely feedback to residents: Faculty perspectives. J Pak Med Assoc. 2015; 65(10): 1069-74. PMID: 26440835

9. Kasi PM, Khawar T, Khan FH, Kiani JG, Khan UZ, Khan $H M$, et al. Studying the association between postgraduate trainees' work hours, stress and the use of maladaptive coping strategies. J Ayub Med Coll Abbottabad. 2007; 19(3): 37-41. PMID: 18444589

10. Saaiq $M$, Khaleeq-uz-Zaman. Residents' perceptions of their working conditions during residency training at PIMS. J Coll Physicians Surg Pak. 2010; 20(6): 4004. Doi: 06.2010/JCPSP.400404

11. Haney EM, Nicolaidis C, Hunter A, Chan BK, Cooney TG, Bowen JL. Relationship between resident workload and self-perceived learning on inpatient medicine wards: a longitudinal study. BMC Med Edu 2006; 6: 35. Doi: 10.1186/1472-6920-6-35

12. Sameer-ur-Rehman, Kumar R, Siddiqui N, Shahid Z, Syed $S$, Kadir M. Stress, job satisfaction and work hours in medical and surgical residency programmes in private sector teaching hospitals of Karachi, J Pak Med Assoc. 2012; 62(10): 1109-12. PMID: 23866463

13. Liptrot S. Problems in medical training won't be solved by working time opt-outs. BMJ. 2014; 349: g5431. Doi:10.1136/bmj.g5431

14. Ahmed N, Devitt KS, Keshet I, Spicer J, Imrie K, Feldman $L$, et al. A systematic review of the effects of resident duty hour restrictions in surgery. Impact on resident wellness, training, and patient outcomes. Ann Surg. 2014; 259(6): 1041-53. Doi: 10.1097/SLA.0000000000000595

15. Williams N, Beamish A, Foster CBEA, Hopson C, Royles D, Hamilton-Fairley $D$, et al. Report of the Independent Working Time Regulations Taskforce. The implementation of the working time directive, 
and its impact on the NHS and healthcare professionals. RCS Publications, 2014. www.rcseng.ac.uk/policy/documents/wtd-taskforcereport-2014

16. Sandhu D. Postgraduate medical education Challenges and innovative solutions. Med Teacher.2018; 40(6): 607-609. Doi: 10.1080/0142159X.2018.1461997

17. Murnaghan ML, Forte M, Choy IC, Abner $E$. Innovations in Teaching and Learning in the Clinical Setting for Postgraduate Medical Education. Members of the FMEC PG consortium; 2011.
18. Weigl M, Hornung S, Angerer P, Siegrist J, Glaser J. The effects of improving hospital physicians working conditions on patient care: a prospective, controlled intervention study. BMC Health Services Research 2013; 13(1): 401. Doi: 10.1186/1472-6963-13-401

19. Kahloon LE. Trainees' perception of learning environment in public teaching hospitals of rawalpindi: a mixed methods study. Pak Armed Forces Med J. 2018; 68 (2): 404-411.

20. Hameed T, Zia N, Khan HS, Zia A, Ahmed R, Hameed $A$, et al. Analysis of level of satisfaction of postgraduate trainees on surgical floor. J Ayub Med Coll Abbottabad. 2019; 31(2): 207-213. 